\title{
Unusual Subcutaneous Swellings on the Hand as Primary Presenting Feature of Sarcoidosis
}

SHEILA MOSCATELLI, MD, Rheumatology Unit, Department of Clinical and Experimental Medicine, Policlinico Monteluce, Perugia, Italy; STEFANO SIMONETTI, MD, Clinica Dermatologica, Azienda Ospedaliera di Perugia; ELENA BARTOLONI BOCCI, MD; ROBERTO GERLI, MD, Rheumatology Unit, Department of Clinical and Experimental Medicine, Policlinico Monteluce, Via Brunamonti, Perugia I-06122, Italy. Address correspondence to Dr. Gerli; E-mail: gerlir@unipg.it. J Rheumatol 2011;38:519-21; doi:10.3899/jrheum.100731

Sarcoidosis usually presents with typical signs and symptoms, often found through chest radiographs. However, sometimes sarcoidosis is diagnosed from unusual manifestations. A soft-tissue swelling in the hands, for example, without significant systemic disease is a rare sign, but it could indicate sarcoid involvement of subcutaneous tissue.

A 41-year-old man presented with a 4-month history of progressive, painless soft-tissue nodular swellings in his left hand. He denied symptoms of systemic illness or history of chronic disease. Examination revealed 2 nodular masses, one with a diameter of $1 \mathrm{~cm}$ on the thenar eminence and the other $2 \mathrm{~cm}$, involving the third metacarpophalangeal joint (Figures 1,2). The masses were nontender, firm, and had well demarcated borders. Routine laboratory studies were unremarkable except for a slightly elevated uric acid level, hypercholesterolemia, and hypertriglyceridemia. At ultrasound evaluation with power Doppler, the subcutaneous lesions were consistent with granulomatous or fatty tissue lesion. Radiographs of both hands showed nodular soft-tissue densities, but no calcification within the masses or lytic bone lesions. Magnetic resonance imaging of the hand confirmed swellings occupying a subcutaneous area from skin surface to deep osteotendinous structures, with interruption of fatty tissue. Histological examination of biopsy tissue revealed dermohypodermitis with nonnecrotizing noncaseating granulomas and plurinucleate giant cells (Figure 3 ). Tuberculosis was ruled out by microscopy and routine microbiological examination. Chest radiographs were unre-

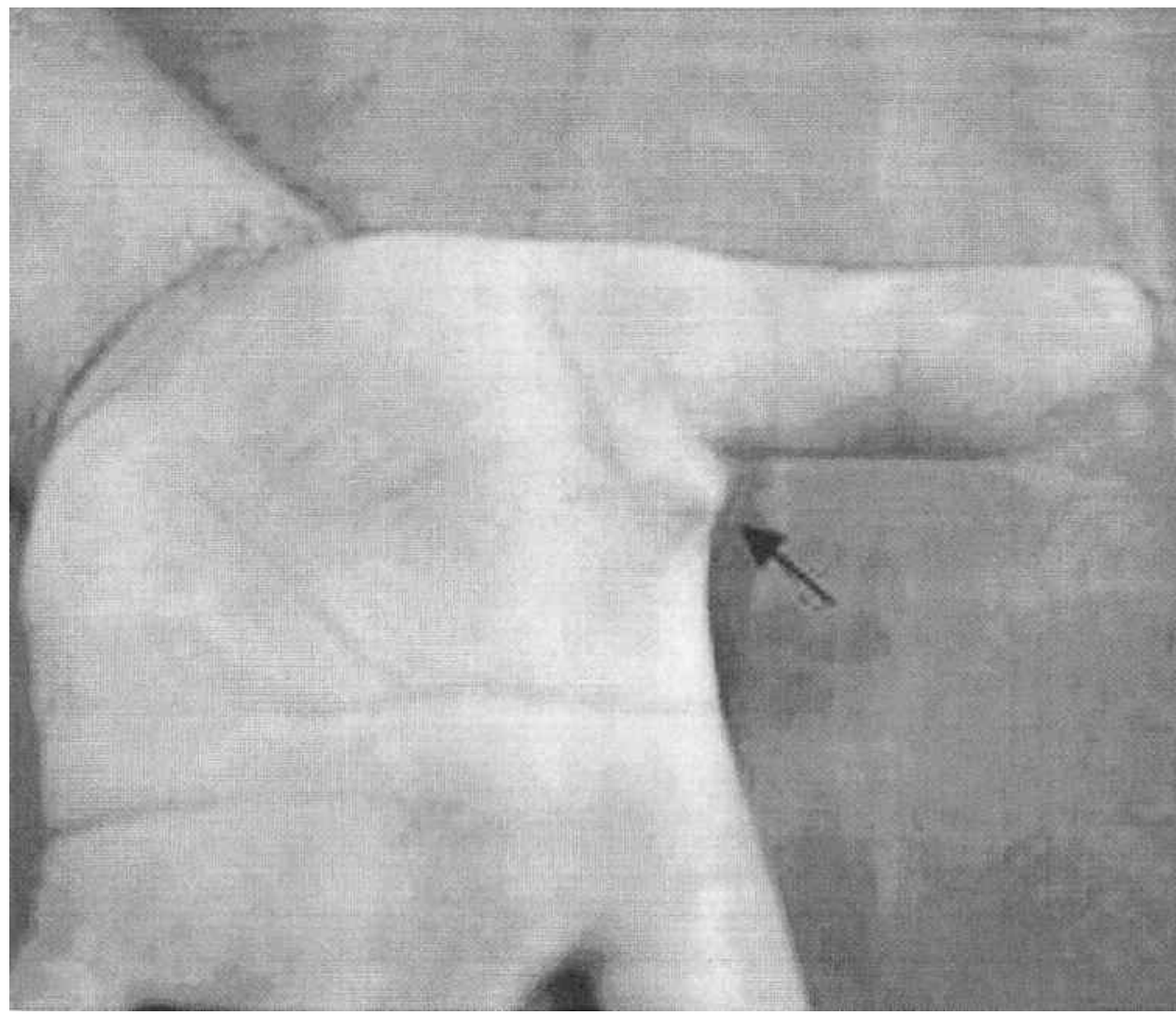

Figure 1. Nodular mass of $1 \mathrm{~cm}$ at thenar eminence. 


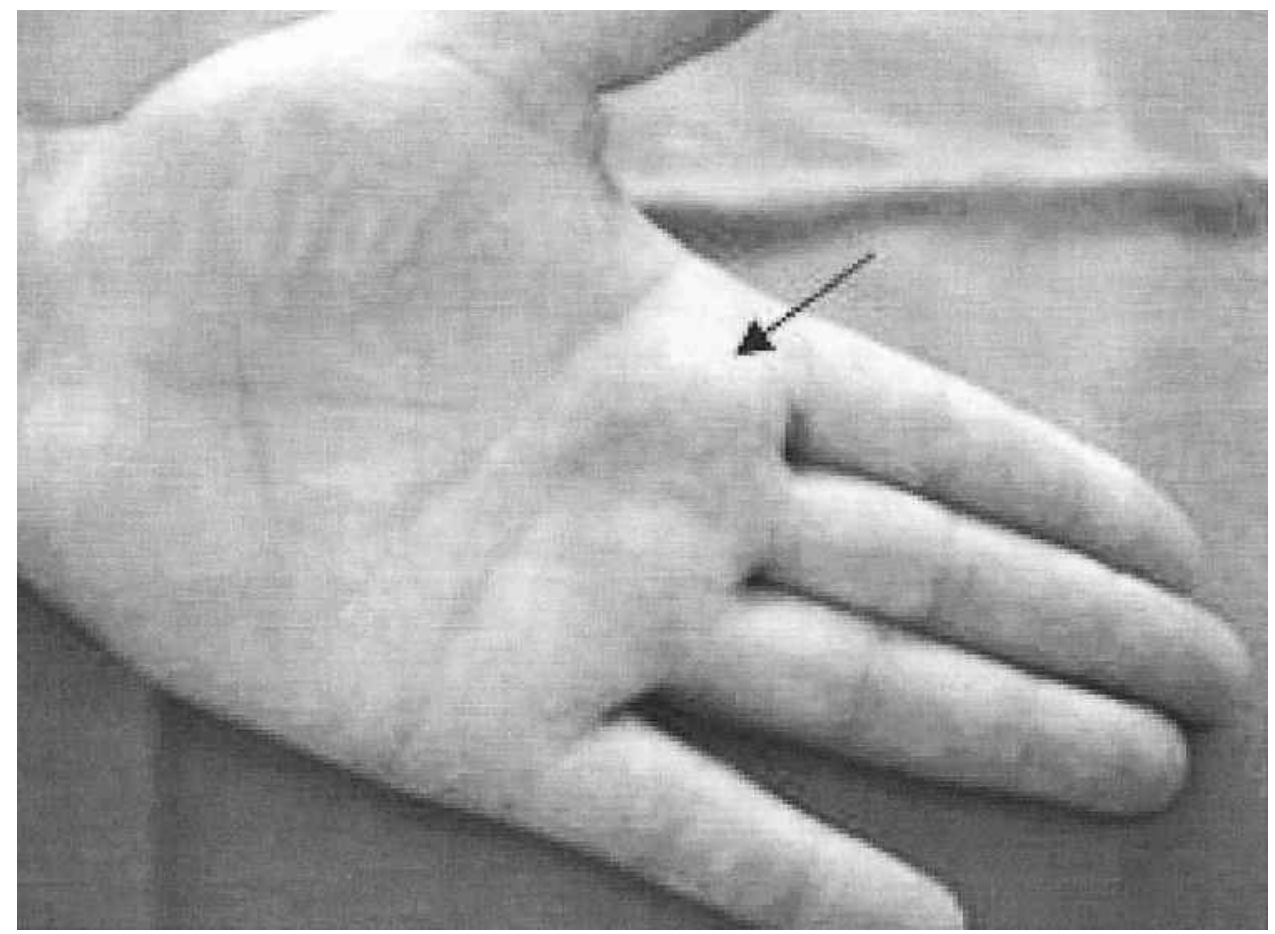

Figure 2. Nodular mass of $2 \mathrm{~cm}$ at third metacarpophalangeal joint.

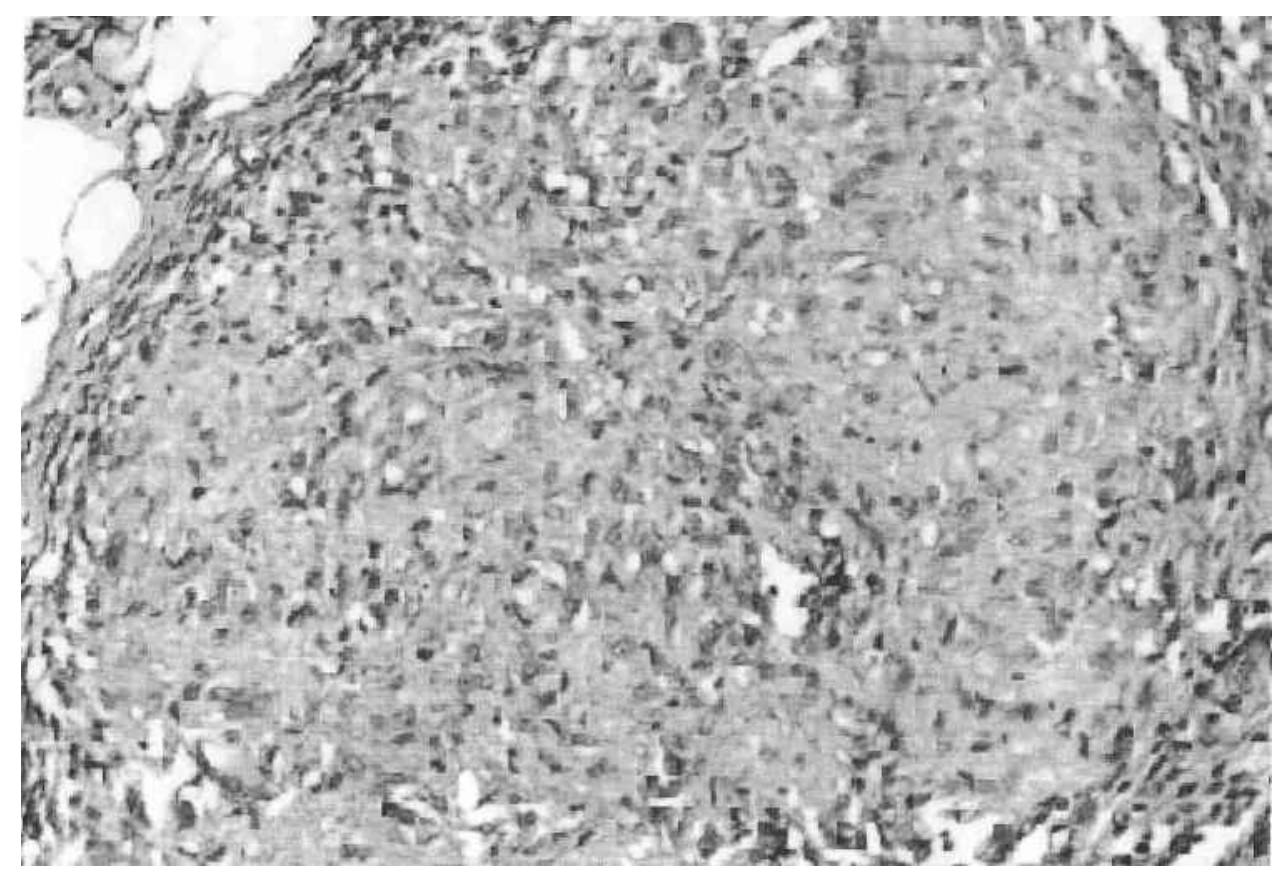

Figure 3. Biopsy tissue revealing dermohypodermitis with nonnecrotizing noncaseating granulomas and plurinucleate giant cells.

markable, but a chest computed tomography (CT) scan showed parenchymal micronodules and bilateral hilar, perihilar, and mediastinal lymphadenopathy. These findings were considered to be consistent with a diagnosis of sarcoidosis with subcutaneous nodular involvement of the left hand.
The patient remained asymptomatic and the hand swellings progressively decreased, until complete resolution without treatment. After 6 months, a control chest CT scan showed a spontaneous resolution of both lung and lymph node involvement.

The case presents some unusual features. Indeed, 
although skin involvement is observed in $9 \%-37 \%$ of the overall patients with systemic sarcoidosis ${ }^{1}$, subcutaneous involvement is the less frequent manifestation of sarcoid-specific skin lesions ${ }^{2,3}$. It is noteworthy, moreover, that sarcoid lesions of the hand occur in only about $0.2 \%$ of cases $^{4}$. In the majority of these cases, they are represented by bone lytic lesions and only occasionally by tendon, skin, or subcutaneous soft-tissue involvement. In addition, sarcoid dactylitis, characterized by noncaseating granulomas invading the phalanges and adjacent soft tissue and anatomically different from spondyloarthritis dactylitis, has been well recognized ${ }^{5,6}$. The most interesting observation, however, is that, to our knowledge, subcutaneous hand involvement is exceptional as a primary presenting feature of this disorder ${ }^{7}$.

From a rheumatological point of view, the significance of this case is that, although sarcoidosis commonly presents with typical signs and symptoms, unusual manifestation should not preclude diagnosis. An atypical soft-tissue swelling in the hands, also in the absence of significant systemic disease, may arouse the suspicion of sarcoid involvement of subcutaneous tissue.

\section{REFERENCES}

1. Yanargag H, Pamuk ON, Karayel T. Cutaneous involvement in sarcoidosis: analysis of the features in 170 patients. Respir Med 2003;97:978-82.

2. Kwon B, Bindra RR, Liakos P, Gelberman RH. Extensive nodular sarcoidosis in the hand. J Hand Surg Br 1997;22:567-8.

3. Imai S, Kubo M, Andou K, Kikuchi K, Matsusue Y. Transition from diffuse cellular infiltration to extensive nodular granuloma as a manifestation of isolated sarcoidosis in the hand: a case report. J Hand Surg Am 2003;28:439-42.

4. Duckworth AD, Hill AT, Beggs I, Patton JT, Salter DM, Porter DE. Sarcoidosis presenting as a proximal phalangeal bony swelling - a case and review of the literature. Hand (NY) 2009 Jun 11 (Epub ahead of print).

5. Olivieri I, Scarano E, Padula A, Giasi V, Priolo F. Dactylitis, a term for different digit diseases. Scand J Rheumatol 2006;35:333-40.

6. Olivieri I, Padula A, Scarano E, Scarpa R. Dactylitis or "sausage-shaped" digit. J Rheumatol 2007;34:1217-22.

7. Marcoval J, Mana J, Moreno A, Peyri J. Subcutaneous sarcoidosis - clinicopathological study of 10 cases. Br J Dermatol 2005;153:790-4. 